\title{
Religiöse Philosophie und philosophische Religion der frühen Kaiserzeit
}

Literaturgeschichtliche Perspektiven. Ratio Religionis Studien I Hrsg. v. Rainer Hirsch-Luipold, Herwig Görgemanns, Michael von Albrecht unter Mitarb. v. Tobias Thum

Religiöse Philosophie und philosophische Religion der frühen Kaiserzeit

Herausgegeben vo RAINER HIRSCH-LUIPOLD HERWIG GÖRGEMANNS MICHAEL VON ALBRECHT unter Mitarbeit von TOBIAS THUM

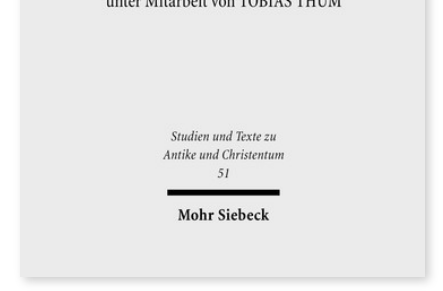

2009. X, 418 Seiten. STAC 51

ISBN 978-3-16-151350-3

DOI 10.1628/978-3-16-151350-3

eBook PDF 94,00€

ISBN 978-3-16-149593-9

fadengeheftete Broschur 94,00€
In der frühen Kaiserzeit werden Traditionen der gelebten Religion verstärkt als Quelle philosophischen Denkens interpretiert und plausibilisiert. Heilige Erzählungen, Riten und Kultgegenstände erscheinen als Reflex göttlicher Wahrheit: sie eröffnen Erkenntnis, die wahres Leben verspricht. Umgekehrt beruft sich philosophische Weltdeutung auf die religiöse Tradition als letzten Erkenntnisgrund. Dieser Verschmelzung religiöser und philosophischer Diskurse, die insbesondere den Platonismus jüdischer, christlicher und pagan-religiöser Provenienz kennzeichnet, entspringen kreative Neudeutungen in beiden Feldern. Im vorliegenden Tagungsband zeichnen ausgewiesene Fachleute aus den Bereichen Klassische Philologie, Theologie, Religionswissenschaft, Judaistik und Philosophiegeschichte ein Panorama der religiös-philosophischen Literatur der frühen Kaiserzeit, über religiös-kulturelle Herkunftsbereiche, Sprachgrenzen und Literaturgattungen hinweg. Die Beiträge reichen von der paganen griechischen und lateinischen Literatur über hellenistisch-jüdische und neutestamentliche Texte bis hin zu Qumran sowie dem gnostischen und hermetischen Schrifttum. Dieser Querschnitt durch die religiös-philosophische Literatur der Kaiserzeit wird ergänzt und vertieft durch exemplarische Studien zu einzelnen Autoren und Texten (Philon von Alexandria, Plutarch, Johannesevangelium, Klemens von Alexandria). Die Beiträge wurden bei der »Impulstagung« des Projekts Ratio Religionis im Februar 2007 an der Georg-August-Universität Göttingen gehalten. Wichtige Quellentexte werden am Schluss zweisprachig dargeboten.

Inhaltsübersicht

Albrecht Dihle: Die griechische Philosophie zur Zeit ihrer Rezeption durch Juden und Christen - Michael von Albrecht: Philosophie und Religion in der lateinischen Literatur der Kaiserzeit - Herwig Görgemanns: Religiöse Philosophie und philosophische Religion in der griechischen Literatur der Kaiserzeit - Gregory Sterling: Alexandrian Jewish Exegetical Tradition: Philosophy as the Handmaid of Wisdom - Reinhard Feldmeier: „Göttliche Philosophie«. Die Interaktion von Weisheit und Religion in der späteren Antike - Devorah Dimant: Time, Torah and Prophecy at Qumran - Zlatko Plese: Gnostic and Hermetic Literature: Oriental Wisdom - Rainer Hirsch-Luipold: Die religiös-philosophische Literatur der frühen Kaiserzeit und das Neue Testament - Adolf Martin Ritter: Christentum und Philosophie als Thema frühkaiserzeitlicher Kirchenväterliteratur Tobias Thum: 'Welche Fülle von Reden!': Plutarchs Schrift De E apud Delphos - Peter Kirchschläger: Der Wahrheitsbegriff im Johannesevangelium - Jane Heath: 2 Cor 4, 7-12: Viewing Paul as an Icon of Christ - Ilinca Tanaseanu: Gräber und Symbole: Tempel im Werk Clemens' von Alexandrien - Fritz Heinrich: Der religiöse Intellektuelle: Apuleius und Ali Schariati

Herwig Görgemanns Geboren 1931; 1959 Promotion; 1965 Habilitation; 1967/1968 Fellow am Center for Hellenic Studies der Harvard University; seit 1972 Professor für klassische Philologie an die Universität Heidelberg; 1997 emeritiert.

Michael von Albrecht war von 1964-1998 Ordinarius für klassische Philologie an der Universität Heidelberg und ist seit 1998 emeritiert.

Rainer Hirsch-Luipold Geboren 1967; seit 2011 Ordentlicher Professor für Neues Testament und Antike Religionsgeschichte an der Universität Bern; seit 2015 zusätzlich Extraordinary Professor an der Stellenbosch University (SA), Department of Ancient Studies.

https://orcid.org/0000-0002-6938-268X

Tobias Thum Geboren 1976; Studium der Klassischen Philologie und der Germanistik; 2010 Promotion; seit 2011 Wissenschaftlicher Mitarbeiter an der Bayerischen Akademie der Wissenschaften und Lehrbeauftragter am Institut für Griechische und Lateinische Philologie der LMU München.

Jetzt bestellen:

https://mohrsiebeck.com/buch/religioese-philosophie-und-philosophische-religion-der-fruehen-kaiserzeit-9783161513503? no_cache=1

order@mohrsiebeck.com

Telefon: +49 (0)7071-923-17

Telefax: +49 (0)7071-51104 